\title{
Effects of instructors' academic disciplines and prior experience with learning management systems: A study about the use of Canvas
}

\author{
Nafsaniath Fathema, Mohammad H. Akanda \\ University of Wisconsin-Madison
}

\begin{abstract}
This study examines the effects of instructors' academic disciplines and prior experience with the learning management system (LMS), Canvas, on current use. Our mixed method study collected data via an online survey from 557 instructors at two United States universities. Quantitative analyses found significant differences in instructors' use of Canvas by their academic discipline and prior Canvas experience. Content analysis of the open-ended responses revealed that, when reporting the strengths and weaknesses of Canvas, while instructors across disciplines reported common strengths, the weaknesses they identified varied according to the features they used for their specific disciplines. Our findings lead us to recommend routine evaluation and assessment of instructors' needs related to LMS. We suggest that, together with general LMS training, campuses design and offer disciplinespecific LMS training to ensure instructors' needs for LMS based on their academic fields are addressed. Also, we propose that universities should design and offer basic and advanced LMS training programs for instructors with different levels of LMS experience.
\end{abstract}

\section{Implications for practice or policy:}

- Instructors' academic disciplines and prior LMS experience effect their LMS use.

- To ensure large-scale instructor adoption of an LMS, universities should make LMS evaluation an integral part of its adoption.

- Universities should offer general and advanced LMS trainings for instructors with different levels of LMS experience.

- Universities should also offer discipline specific training and professional development on LMS usage to address instructors' needs for LMS based on their academic fields.

- Keywords: experience, learning management system, LMS, Canvas, instructor, academic discipline, prior experience, mixed- method

\section{Introduction}

Although learning management systems (LMSs) have become a basic educational technology to support higher education in the United States, research on their usability is in its infancy (Orfanou, Tselios, \& Katsanos, 2015). Indications are that instructors use few of the systems' features that support instruction (Allen \& Seaman, 2010; Dahlstrom, Brooks, \& Bichsel, 2014; Jaschik \& Lederman, 2014). Indeed, "the reality of instructional technology use is in the relationship between the new instructional technologies and the faculty members' individual and organizational context and their personal histories" (Spotts, 1999, pp. 93-94). Though LMSs offer a gateway to innovative technology-enhanced teaching and learning (Sinclair \& Aho, 2017) and $99 \%$ of universities in the United States have LMSs to facilitate their teaching and learning processes, only half the instructors use it on a regular basis, and the majority of those instructors do not use the systems' advanced tools, which have potential to improve student learning (Dahlstrom et al., 2014). When educational technologies were being introduced, instructors were not so interested in integrating technologies into their curricula, and even technology-proficient teachers did not necessarily believe these tools were valuable (Steel, 2009). Reasons given for this lack of uptake included computer illiteracy, computer phobia, disinterest, lack of equipment, and lack of time to learn appropriate uses (Wentworth, Graham, \& Tripp, 2008). This background suggests that a university adopting an LMS doesn't necessarily ensure the full utilisation of it by instructors, rather, it encourages instructors to view learning technology as a big challenge (Orfanou et al., 2015; Wentworth et al., 2008; Zayim, Yildirim, \& Saka, 2006). Since, instructors are the key decision makers to use (or not to use) an LMS for teaching, successful implementation largely depends on the users' perceptions about the system and to what extent they use it for teaching (Fathema, Shannon, \& Ross, 2015; Fathema \& Sutton, 2013; Kim \& Leet, 2008; Lee, Kozar, 
\& Larsen, 2003; Orfanou et al., 2015). Research indicates that "user satisfaction is highest for basic LMS features and lowest for features designed to foster collaboration and engagement" (Dahlstrom et al., 2014, p. 11). To ensure large-scale LMS adoption, it is important to understand instructors' different needs and expectations of an LMS as a tool to support instructional activities (Ertmer, Ottenbreit-Leftwich, Sadik, Sendurur, \& Sendurur, 2012; Woodell \& Garofoli, 2003).

Prior studies explored instructors' perceptions of LMSs' ease or complexity of use, usefulness, attitude towards use, intention to use, and actual use (Fathema et al., 2015; Fathema \& Sutton, 2013; Lee et al., 2003; Panda \& Mishra, 2007; Pituch \& Lee, 2006; Weaver Spratt, \& Nair, 2008) and reported poor selfefficacy, fear of technology, and lack of training as factors that cause differences in LMS usage behaviour (Fathema et al., 2015; Sinclair \& Aho, 2017). Studies also indicated that organisational support plays an important role in improving LMS self-efficacy by providing technical assistance and improving system quality (i.e., user friendliness, easy accessibility, and reliability) of LMSs (Fathema et al., 2015; Zheng, Wang, Doll, Deng, \& Williams, 2018). Improved LMS self-efficacy leads to more frequent use of LMS by instructors (Fathema et al., 2015).

Although prior research on LMS adoption in higher education proposed and validated models of LMS acceptance by instructors and students, most of these studies explored instructor and student views of LMS in general, irrespective of discipline. Although basic respect for knowledge and intellectual inquiry is common to all disciplines, each field has its own features, such as epistemological principles, language, and goals to meet specific requirements of the specific disciplines. It follows that instructors' teaching practices vary (Neumann, Parry, \& Becher, 2002). For example, hard science instructors teach theories, formulae, and calculations, while soft-discipline instructors spend more time on discussions, case studies, and interpretations. To support the teaching processes, each discipline may use educational technologies in different ways and to different extents. Studies of computer-mediated communication in distance education revealed disciplinary differences in the use and appropriateness of different technologies for teaching (Arbaugh, 2005; Lowenthal, Wilson, \& Parrish, 2009; Smith, Torres-Ayala, \& Heindel, 2008). Given that disciplinary differences exist in teaching practices, instructors' use of LMSs for instruction may differ across disciplines. Therefore, we seek a deeper understanding of how instructors in different disciplines use an LMS, and the extent to which they use its features. In this study we identify the disciplinary differences in LMS use by higher education instructors.

While reporting the effect of prior technology experience on attitude towards technology use or actual use of technology (i.e., LMS or any other technologies), prior research indicated different findings. Orfanou et al. (2015) reported users' (students') prior experience with LMS is positively associated with their perceived usability of LMSs. Sauro (2011) reported users' prior website usage experience positively affects their perceived attitudes towards websites usability. Meyen, Tange, and Lian (1999) reported that lack of technical experience was the most significant challenge to use the internet for instructional purposes, and institutions were not prepared for this growing demand. West, Waddoups, and Graham (2007) reported instructors face technical and integration challenges at the initial stages of LMS use, but later as they become more familiar with the LMSs, they feel more comfortable and try to adopt the tool for different types of pedagogies. Buzzard, Crittenden, Crittenden, and McCarty (2011) found instructors perceived a positive relationship between instructional technology use and engagement in the learning process and their outcomes. They also reported most instructors were eager to learn and teach with a variety of digital technologies. In this study, we further explored this area, more specifically, we examined the effect of prior LMS experience on instructors' current use of LMS for instruction.

The objectives of our study were to determine the effect of academic discipline and prior LMS experience on instructors' LMS usage behaviour; and to explore instructors' views (by discipline) of the strengths and weaknesses of an LMS.

\section{Theoretical and contextual framework}

To explore cross-discipline similarities and differences of instructors' use of LMSs, we examined instructors' use of Canvas for graduate and undergraduate instruction. Established in 2010, Canvas is the world's fastest growing learning management platform, used in 30\% of United States higher education institutions and many K-12 schools for kindergarten through Grade 12 (Instructure, 2019). 
To examine instructors' use of Canvas by academic discipline we first classified the academic areas into four major categories. To do so, we followed Biglan's (1973a) classification of academic disciplines. In his research on the characteristics of academic subject matter, Biglan (1973a) presented three important features of academic areas: (a) the existence of a single paradigm (hard vs. soft); (b) their concern with practical application (pure vs. applied); and (c) their concern with life systems (life vs. nonlife). In a subsequent study he reported that depending on the characteristics of this academic areas, scholars differ in their commitment to teaching, research, and service (Biglan, 1973b). Biglan (1973a) suggested scholars should use at least two dimensions when conducting research about academic subject matter. In this study, we considered the first two dimensions and categorised instructors' academic disciplines into four groups: hard-pure, hard-applied, soft-pure, and soft-applied. To define the four groups, we followed four prior studies where the four academic categories were clearly explained (Biglan 1973a, 1973b; Neumann et al., 2002; Smith et al., 2008). Hard-pure disciplines (e.g., physics, chemistry, mathematics) are related to natural sciences and focus on theoretical explorations, the contents are typically fixed, cumulative and quantitative (Biglan, 1973a; Smith et al., 2008). Hard-applied disciplines (e.g., engineering, pharmacy, medicine) are focused on product and techniques, content knowledge is atomistic and cumulative, and directed towards how knowledge can be applied and make changes to the real world (Biglan, 1973a; Smith et al., 2008). Soft-pure disciplines (e.g., liberal arts, history, philosophy) are freer ranging, nonlinear and qualitative with knowledge building being a formative process, and teaching activities being largely constructive and interpretative (Neumann et al., 2002). The soft-applied disciplines (e.g., business, education, human science, nursing) concern accumulation of knowledge by a reiterative process shaped by practically practiced knowledge and espoused theory (Neumann et al., 2002) (Table 1).

Table 1

Classification of academic disciplines following Biglan's 1973 model of disciplines

\begin{tabular}{lll}
\hline Dimension 2 & \multicolumn{1}{c}{ Hard } & Dimension 1 \\
\hline Pure & $\begin{array}{l}\text { Content is typically fixed, } \\
\text { cumulative and quantitative. } \\
\text { Examples: mathematics, } \\
\text { statistics, biological sciences, } \\
\text { geo-sciences, chemistry, } \\
\text { biochemistry, physics. }\end{array}$ & $\begin{array}{l}\text { Content knowledge is formative, constructive } \\
\text { and interpretative, non-linear and qualitative. } \\
\text { Examples: } \\
\text { Social sciences: sociology, anthropology, } \\
\text { social work, psychology, economics. }\end{array}$ \\
& $\begin{array}{l}\text { Fine arts: theatre, music. } \\
\text { Communications: journalism, }\end{array}$ \\
& $\begin{array}{l}\text { Communication disorders. } \\
\text { content is atomistic, cumulative } \\
\text { and product and technique } \\
\text { oriented and focuses on factual } \\
\text { understanding. }\end{array}$ & $\begin{array}{l}\text { Content knowledge is reiterative and holistic } \\
\text { and focuses on enhancement of professional } \\
\text { practice. }\end{array}$ \\
& $\begin{array}{l}\text { Examples: engineering, } \\
\text { agriculture, forestry, wildlife } \\
\text { science, pharmacy, medicine. }\end{array}$ & $\begin{array}{l}\text { business, education, family studies, } \\
\text { consumer sciences, design sciences, nursing. }\end{array}$ \\
& &
\end{tabular}

Our mixed method study explores discipline-specific differences of instructors' attitudes toward Canvas under these four categories. Our study is important for two reasons. First, through quantitative data analyses, our study identifies differences in instructors' Canvas use by their academic disciplines and prior Canvas experience. Second, through content analyses our study reports strengths and weaknesses of Canvas as indicated by instructors and then categorises the responses by discipline. Our findings will help LMS developers, researchers, and practitioners learn about the effect of academic discipline and prior LMS experiences on instructors' Canvas usage, and the instructors' concerns about the system. These findings also will help determine whether instructors' have the relevant competencies or experiences to integrate an LMS into their instructional practices (Kale \& Goh, 2014).

\section{Methods}

Our study is a part of an institutional review board-approved larger study. Through an online survey, we collected anonymous and non-identifiable data from instructors. The online survey had 28 Likert-scale items and 3 open-ended questions. For this specific study, we only used the items relevant to the study 
context. To measure actual use (AU) of LMSs by instructors, we used a 3-item Likert-scale question with a 7-point scale (1 being the lowest use and 7 being the highest use) where instructors reported to what extent they used Canvas at three different time points (overall, last month, and last week) for instructional purposes. The AU construct was adapted from a prior study (Malhotra \& Galletta, 1999) and re-worded to make it relevant to our context. Reliability of the AU construct was $(\alpha) 0.963$. To measure instructors prior experience (PEx) with Canvas we used a close-ended question (How long have you been using Canvas?) with three options to choose from: less than 6 months, 6 months to 1 year, and more than 1 year. The three types of prior experience groups were termed as little-experience, moderate-experience, and highexperience. We also collected information on instructors' discipline (IDis) through a close-ended question with a list of disciplines to choose from. Later, following Biglan's 1973 model, we categorised the responses to this question under four categories: hard-pure, hard-applied, soft-pure, and soft-applied. We also used two open-ended questions where instructors reported the strengths and weaknesses of Canvas. Two content experts reviewed the survey items, and the survey was pilot-tested before the final data collection.

\section{Participants and study context}

Using a purposive sampling method for data collection, we selected two research-intensive public universities with similar institutional characteristics. Both of the universities followed similar LMS adoption paths. Before adopting Canvas, both of the universities had Blackboard as their LMS. To ensure smooth transition from Blackboard to Canvas, both of the universities provided options to their instructors to use either or both for at least a year before fully switching to Canvas. Both had LMS support centres which routinely offered LMS training and technical support to faculty and graduate teaching assistants; however, these sessions were not mandatory. In addition to the routine trainings, the centres provided LMS support whenever requested. During data collection, one of the universities was in its third year and the other was in its second year of using Canvas exclusively. It was not mandatory for the instructors to use Canvas, rather, they had the option to use none, some, or all features of Canvas. To support their instructional activities, instructors were also permitted to use any other publicly available software over and beyond Canvas.

We collected data from Canvas users with teaching responsibilities from the two universities. The data collection took 4 months. We first gathered faculty and teaching assistants' email addresses from university websites. We then sent email invitations with the online survey link to all 2,330 university instructors, irrespective of whether they used Canvas. After the first email, we sent two reminder emails (one in the second month and one in the fourth month) to encourage the instructors to complete the survey. Participation was voluntary and no incentive was offered. Response rates were $24 \%$ (557) of the potential Canvas users across both universities, with 53\% male and 47\% female. The academic ranks of the respondents were $19 \%$ professors, $27 \%$ associate professors, $19 \%$ assistant professors, $8 \%$ lecturers, $7 \%$ instructors, $14 \%$ graduate teaching assistants, and $6 \%$ not disclosed. Of the respondents, $23 \%$ had been using Canvas for less than 6 months, $37 \%$ for 6 months to 1 year, and $40 \%$ for more than 1 year. We used the term instructor to refer to all of these respondents.

\section{Data analysis}

We followed a 2-step procedure in our data analysis. First, we conducted factorial ANOVA to quantitatively analyse the effect of instructors' prior Canvas experience (PEx) and their discipline (IDis) on their actual Canvas use (AU). Next, we used content analysis to examine the descriptive responses to the open-ended survey questions about Canvas strengths and weaknesses to triangulate and validate our quantitative results and to support or elaborate on our findings from the first step.

The descriptive statistics of instructors' academic discipline (IDis), instructors' prior Canvas experience (PEx) and instructors' actual use of Canvas (AU) are presented in Table 2. The factorial ANOVA results indicated no interaction effect between instructors' prior experience (PEx) and discipline (IDis) on actual use (AU). However, the results showed a significant main effect of PEx, $[F(2,545)=27.849, p<.001$, partial $\left.\eta^{2}=0.093\right]$ and a significant main effect of IDis, $\left[F(3,545)=3.614, p=.013\right.$, partial $\left.\eta^{2}=0.020\right]$ on AU. Two LSD post hoc tests were conducted to determine the pairwise differences by factors (PEx and IDis). In terms of discipline (IDis), we found that instructors from soft-applied disciplines used Canvas significantly more than instructors from hard-pure, hard-applied, and soft-pure disciplines. No other pairwise comparisons were statistically significant (Figure 1). 
Table 2

Descriptive statistics: Instructors' academic discipline (IDis), instructors' prior Canvas experience (PEX), and instructors' current actual use of Canvas (AU)

\begin{tabular}{|c|c|c|c|c|}
\hline $\begin{array}{c}\text { Instructors' prior } \\
\text { Canvas experience } \\
\text { (PEx) }\end{array}$ & $\begin{array}{c}\text { Instructors' } \\
\text { discipline (IDis) }\end{array}$ & $\begin{array}{c}\text { Number of } \\
\text { Canvas } \\
\text { users }\end{array}$ & $\begin{array}{l}\text { Actual use (AU) } \\
\text { Mean }\end{array}$ & $S D$ \\
\hline \multirow{5}{*}{$\begin{array}{l}\text { Less than } 6 \text { months } \\
\text { (little-experience) }\end{array}$} & Hard-pure & 48 & 12.17 & 6.02 \\
\hline & Hard-applied & 26 & 11.35 & 6.71 \\
\hline & Soft-pure & 30 & 9.97 & 5.31 \\
\hline & Soft-applied & 25 & 14.12 & 4.75 \\
\hline & Total & $129(23 \%)$ & 11.87 & 5.89 \\
\hline \multirow{5}{*}{$\begin{array}{l}6 \text { months to } 1 \text { year } \\
\text { (moderate- } \\
\text { experience) }\end{array}$} & Hard-pure & 63 & 14.17 & 5.26 \\
\hline & Hard-applied & 64 & 15.48 & 5.18 \\
\hline & Soft-pure & 26 & 14.46 & 5.60 \\
\hline & Soft-applied & 55 & 15.89 & 5.00 \\
\hline & Total & $208(37 \%)$ & 15.07 & 5.22 \\
\hline \multirow{6}{*}{$\begin{array}{l}\text { More than } 1 \text { year } \\
\text { (high-experience) }\end{array}$} & Hard-pure & 70 & 15.89 & 5.24 \\
\hline & Hard-applied & 52 & 15.35 & 5.78 \\
\hline & Soft-pure & 41 & 16.98 & 4.81 \\
\hline & Soft-applied & 57 & 17.46 & 4.52 \\
\hline & Total & $220(40 \%)$ & 16.37 & 5.16 \\
\hline & Grand total & $557(100 \%)$ & & \\
\hline
\end{tabular}

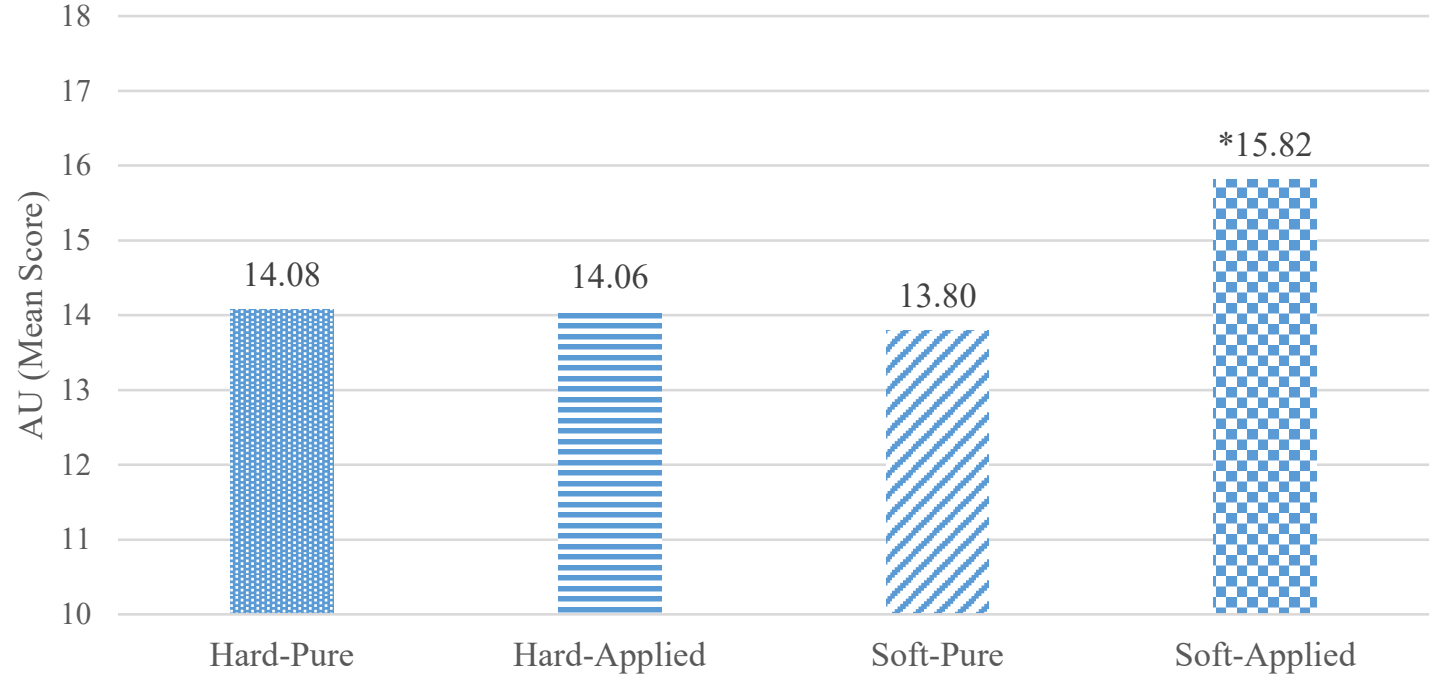

Figure 1. Faculty use of Canvas by discipline category

Note. *Significant pair-wise difference between soft-applied and all other categories

In terms of prior Canvas experience (PEx), we found significant pair-wise differences in instructors' actual use (AU) of Canvas, between all pairs of the three experience groups (little-experience, moderateexperience, and high-experience). The high-experience group used Canvas significantly more than the moderate-experience group and the little-experience group. The moderate-experience group used Canvas more than the little-experience group and less than the high-experience group. The little-experience group used Canvas less than the moderate-experience group and the high-experience group. These results indicated that the more Canvas experience the instructors had, the more they used the system (Figure 2). 


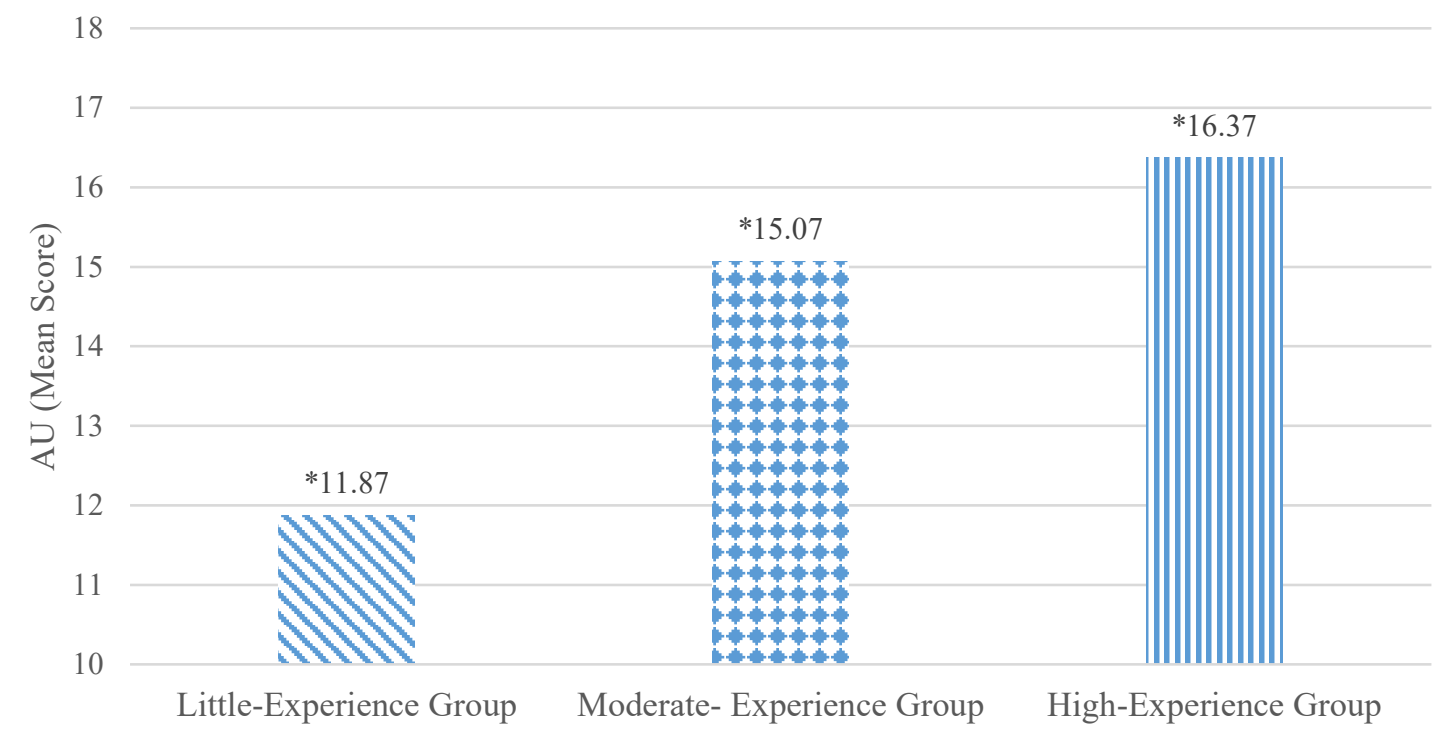

Figure 2. Faculty use of Canvas by prior Canvas experience

Note. *Significant pair-wise differences among all pairs of the three experience groups

\section{Open-ended responses analysis}

To explore instructors' perspectives on Canvas by discipline, we content-analysed the two open-ended questions which asked instructors to report on the systems' strengths and weaknesses. For each question, we grouped the responses into categories (Miles \& Huberman, 1994). We calculated the frequency of each category and ranked accordingly. Though this approach has some limitations (i.e., some ambiguous comments fit into multiple categories, or the questions could not capture all respondent perceptions), through our thematic analyses we captured the most significant strengths and weaknesses that instructors reported. We grouped the responses about Canvas into four categories:

1. Use: comments about user friendliness and ease or complexity of use;

2. Features: comments about specific features;

3. Communication: comments about communicating with students via Canvas, connecting with other software, integrating with multiple courses; and

4. Miscellaneous: comments about other issues, including online support, lack of interest in using.

The responses that reported multiple issues that fell into different categories were multiply coded. We separately examined $25 \%$ of the same survey scripts and categorised the comments. Interrater reliability of approximately $92 \%$ was established after resolving disagreements through discussion. We each separately coded half of the remaining of the transcripts. When asked to report strengths of Canvas, 314 instructors responded. We coded and grouped the 314 responses into the categories, resulting in 785 cases. We received 323 responses about Canvas weaknesses that we coded and grouped into categories, giving us 595 cases.

\section{Canvas strengths}

Our analysis of Canvas' strengths found no significant differences in responses based on instructors' academic discipline (IDis). Of the 785 cases, $40 \%$ related to ease of use, 38\% praised Canvas features, $18 \%$ mentioned communication tools, and $4 \%$ cited other strengths (Figure 3 ). 


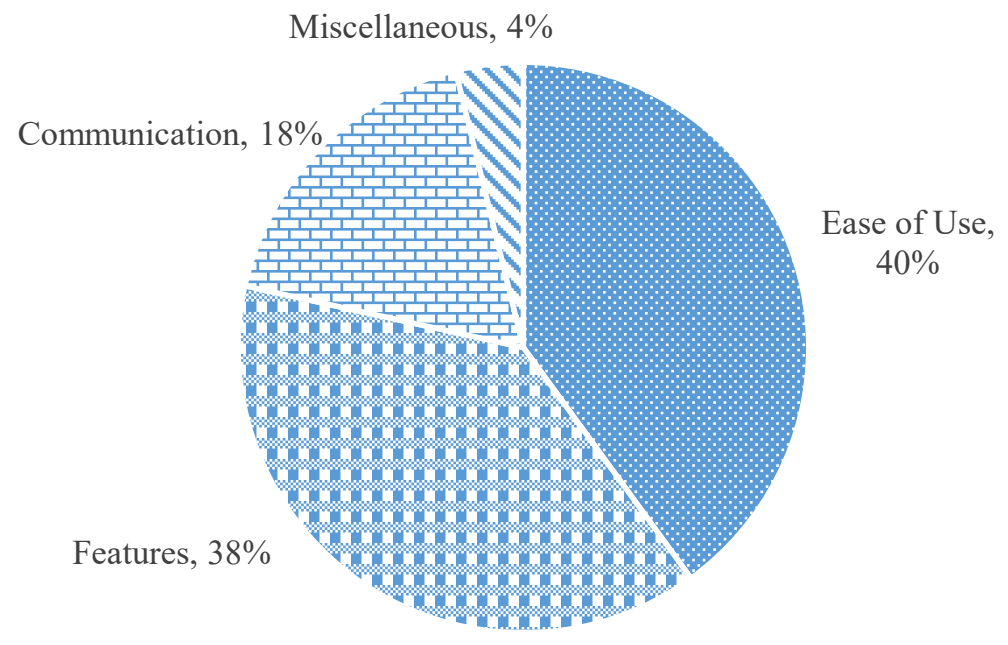

Figure 3. Strengths of Canvas: Instructors' responses by category

We further analysed the responses to find out the specific strengths mentioned in each of the four categories. From our analyses we found that, instructors mostly mentioned similar issues as strengths of Canvas under these four categories. Comments on Canvas' strengths did not vary by academic discipline (IDis). Some of the representative quotes were:

[E]asiness to use, includes most of the feature that I need.

Everything is tied together. Gradebook is built upon assignments and quizzes, etc. Incorporation of rubrics is very straightforward. Communicating with students directly is very easy.

$[\mathrm{O}]$ rganizing lecture material using a variety of formats, directing students through material.

Ability to administer quizzes, post files, and update students on grade progress; easier page editing and linking than Blackboard (although I am providing feedback for further improvement needed); doesn't time out after extended idleness; sends student reminder of approaching due dates.

[M] uch easier learning curve than previously used learning platform I used (eCollege), WAY faster, way easier, way more flexible. I am in control of how my course is organized. Also, especially love the ability to post media easily and record video clips. And also love the online testing. I use it for in class quizzes and a couple midterms. I especially like that you can do much more than regular MCQ's and can embed pictures/graphs etc.

Cross-disciplinary Canvas weaknesses

Out of the 595 cases related to weaknesses of Canvas, $54 \%$ of responses described the complexity of using the system, $31 \%$ reported on complex features, $9 \%$ reported on communication problems, and $6 \%$ reported miscellaneous other weaknesses (Figure 4). 


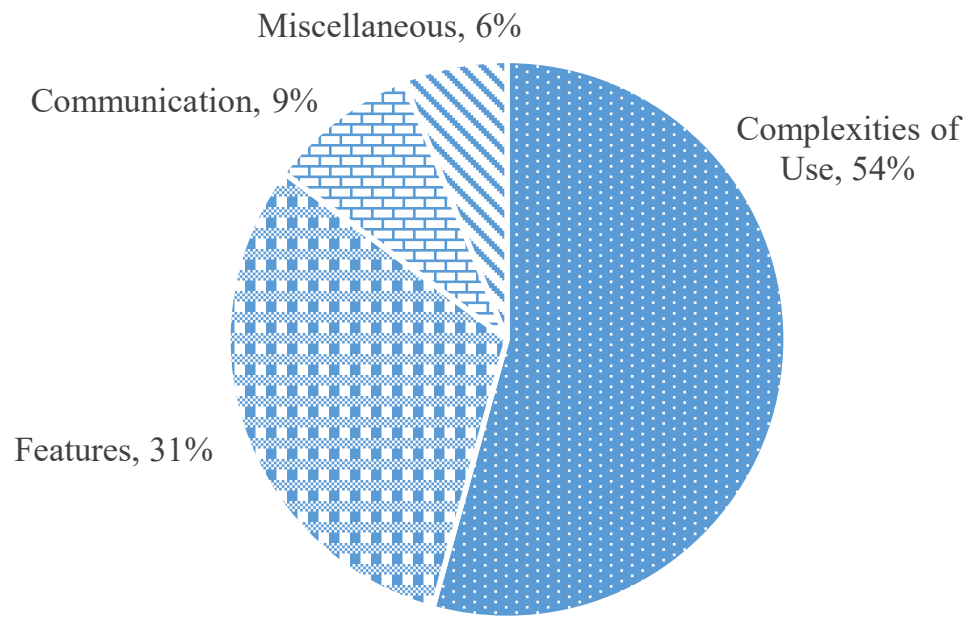

Figure 4. Weaknesses of Canvas: Instructors' responses by category

We further analysed the responses to explore the specific weaknesses mentioned in each of the four categories. Irrespective of academic discipline (IDis), instructors criticised aspects of Canvas' gradebook, system speed and navigation, and general interface and design. The cross-disciplinary nature of these problems could be due to all instructors using the Canvas gradebook and to speed, navigation, interface, and design affecting all Canvas functions, regardless of instructors' discipline. Table 3 shows how instructors from different disciplines had similar comments on the weaknesses of Canvas.

Table 3

Cross-disciplinary Canvas weaknesses as indicated by instructors

\begin{tabular}{|c|c|c|c|}
\hline $\begin{array}{l}\text { Faculty } \\
\text { discipline }\end{array}$ & Gradebook & $\begin{array}{l}\text { Speed and } \\
\text { navigation }\end{array}$ & Interface and design \\
\hline Hard-pure & $\begin{array}{l}\text { "I like the basic functioning of the } \\
\text { gradebook, but without some flexibility, } \\
\text { it is an awful product." }\end{array}$ & $\begin{array}{l}\text { "Access speed is } \\
\text { painfully slow." } \\
\text { "Very complicated to } \\
\text { be operated." }\end{array}$ & $\begin{array}{l}\text { "Isn't at all intuitive in } \\
\text { its design." }\end{array}$ \\
\hline $\begin{array}{l}\text { Hard- } \\
\text { applied }\end{array}$ & $\begin{array}{l}\text { "Cannot figure out the grade book." } \\
\text { "I'd like the gradebook to be a little more } \\
\text { flexible - I can never quite get it to deal } \\
\text { with, for example, extra credit assignments } \\
\text { the way I would like. I'd really like the } \\
\text { rubric authoring to be more flexible - } \\
\text { sending a rubric to a colleague, editing a } \\
\text { rubric - both of these are quite clunky at } \\
\text { present." }\end{array}$ & $\begin{array}{l}\text { "It is terribly } \\
\text { difficult to } \\
\text { navigate." }\end{array}$ & $\begin{array}{l}\text { "The platform is not } \\
\text { visually appealing and } \\
\text { not intuitive." } \\
\text { "Not intuitive." }\end{array}$ \\
\hline Soft-pure & $\begin{array}{l}\text { "Lack of direct upload from Scantron } \\
\text { services (i.e., grading) to Canvas grading." }\end{array}$ & $\begin{array}{l}\text { "It is frustrating } \\
\text { and time } \\
\text { consuming to } \\
\text { navigate." }\end{array}$ & $\begin{array}{l}\text { "It could be made } \\
\text { much more intuitive } \\
\text { than it is currently." } \\
\text { "Complex interface } \\
\text { that is not intuitive." } \\
\text { "The user interface is } \\
\text { so badly designed that } \\
\text { it is nearly hopeless." }\end{array}$ \\
\hline $\begin{array}{l}\text { Soft- } \\
\text { applied }\end{array}$ & $\begin{array}{l}\text { "The gradebook provides so little } \\
\text { flexibility." } \\
\text { "very difficult to understand } \\
\text { gradebook/grading functions; too many } \\
\text { clicks are necessary; not streamlined." }\end{array}$ & "Difficult to use." & $\begin{array}{l}\text { "Canvas is confusing } \\
\text { in its terminology." }\end{array}$ \\
\hline
\end{tabular}


Discipline-specific weaknesses of Canvas

Some comments on Canvas weaknesses varied by discipline category. For example, instructors from hardpure and hard-applied disciplines mostly commented on complexity in writing formulas and uploading/downloading large image, graphic, or video files. Instructors from soft-pure and soft-applied disciplines mostly related problems with communicating through Canvas. Table 4 presents representative comments. These findings about the common and discipline-specific weaknesses of Canvas guide us in identifying the areas where Canvas needs improvements.

Table 4

Discipline-specific Canvas weaknesses as indicated by instructors Hard-pure and hard-applied Soft-pure and soft-applied

\begin{tabular}{ll}
\hline (Comments were mostly on writing formulas and & (Comments were mostly on communicating \\
uploading/downloading larger image, graphic or & through Canvas).
\end{tabular}
video files).

"Quizzes- basic scientific notation, tolerances and trailing zero support non-existent- formula based quizzes an absolute mess for STEM."

"I have video and audio files that are too large for the program to compress and embed in a page."

\section{Discussion and implications}

We explored the effects of instructors' discipline and prior Canvas experience on their actual use of Canvas. We also examined the instructors' views of the strengths and weaknesses of Canvas by their disciplines. Our results revealed statistically significant differences in instructors' use of Canvas by academic discipline and prior Canvas experience. We found that instructors from soft-applied disciplines used Canvas significantly more than the instructors from the other three discipline categories. Our findings are in line with prior findings. For example, Guidry and BrckaLorenz (2010) found that instructors from professional, business, and education (soft-applied disciplines) use educational technologies more than instructors from other disciplines. Also, Lam, McNaught, Lee, and Chan's (2014) study on students' perspectives of technology use for learning found that students in Applied disciplines used the web-based communication tools more as compared to students in Pure disciplines. While exploring differences in usage of courselearning technology across disciplines, Buzzard et al. (2011) reported business and economics instructors use that technology more than fine arts and life science instructors. The variation we find in Canvas use by discipline category could be due to difference in technology competence, per findings by Soomro, Zai, and Jafri (2015) that indicate faculty competence with technologies significantly differs by academic discipline.

Our results also indicate that prior experience has a significant positive effect on instructors' use of Canvas. Instructors with more experience with Canvas use the system significantly more than the instructors with less experience. This finding indicates that experience with an LMS helps instructors get used to it and ensures further use. University contextual factors could explain these findings. The Canvas support centres of both universities routinely offered training and technical support to instructors. As these training sessions were not mandatory for the instructors, not all of the respondents attended the sessions. Therefore, those who attended might have learned and adopted Canvas more quickly and used it more frequently than instructors who did not attend sessions. The training sessions were standardised and designed to cover basic technical/navigational issues and did not support solving advanced, discipline-specific problems that instructors, irrespective of discipline, might face. The content of these sessions might have been inadequate for instructors who needed advanced discipline-specific help. This lack could have led to them to use Canvas less frequently than instructors from other discipline categories.

Our content analyses suggest that category of academic discipline influences instructors' views of Canvas. The weaknesses instructors reported varied by category, likely because different disciplines require varied LMS features. Depending on discipline-specific needs, some instructors use some features more than others. This was apparent in the instructors' responses where they only mentioned the weaknesses they found on the specific LMS features they use more and are familiar with. Therefore, our empirical findings first suggest that it is not always wise to generalise the factors that affect instructors' use of an LMS across 
disciplines. Rather, it is important to find out the discipline-specific differences. Second, by providing discipline-specific analyses of the strengths and weaknesses of Canvas, our findings explicated weaknesses of Canvas as perceived by instructors from different disciplines. The practical implications of our study include reporting the areas where Canvas is weak and needs improvements. Our findings lead us to suggest that universities routinely evaluate their LMSs performance and conduct faculty LMS needs assessments, offer general and advanced training to instructors, and provide discipline-specific professional development on LMS use.

\section{Routine LMS evaluation and needs assessment}

To ensure large-scale instructor adoption of an LMS, universities should make system evaluation an integral part of its adoption. Continuous evaluation of system performance would monitor how instructors use the system, where they encounter problems, and what university and departmental information technology staff could do to better support instructors and ensure their greater use of the LMS. As part of the system evaluation, universities should collect data from instructors on their LMS experiences and assess their needs to make better use of the system.

\section{General training}

When a university introduces an LMS, it should require training for all instructors. In addition, a university should offer introductory LMS training for all new instructors irrespective of academic discipline and prior experience with an LMS. This training should cover the basic features to familiarise instructors with the system and help them get ready to work with it.

\section{Advanced training}

Our findings also suggest that a one-size-fits-all type of training is not sufficient to meet the varying LMS needs of instructors from different disciplines. Though instructors do ask general LMS interface questions during workshops, they face more complex, context-specific issues when they use LMSs on a daily basis (Sanga, 2016). Universities can influence faculty perception of the value of the LMS by providing customised workshops about specific LMS functions and features (Zheng et al., 2018). Therefore, we suggest, in addition to offering standardised LMS trainings for all instructors in general, universities should focus on offering more specific and specialised LMS training programs. Together with the introductory training programs, universities should design and offer advanced programs for instructors who have different levels of LMS experiences.

\section{Training and professional development by discipline}

To provide sufficient LMS support for all instructors, assistance must be specific to each discipline. Regularly conducted needs assessments can help university staff plan such trainings. Identifying these specific areas is important (Kale \& Goh, 2014), and instructors would benefit from knowing about features found to be useful for their specific academic fields.

\section{Conclusion}

Although our study advances understanding of differences and actual use of LMS by instructors' academic discipline and prior LMS experience, these findings are not readily generalisable because the study is based on self-reported data on one system from only two universities. A study with a larger sample may verify our findings. Future research could draw on direct observations and faculty log-in data to explore more representative information and gain a deeper understanding of instructors' competency with and their use of the systems.

In addition, our results suggest that instructors' prior LMS experience and academic discipline can affect use of the system. However, our findings do not identify discipline-specific instructors' LMS needs. Future work might identify a quantitative model to reveal the discipline-specific needs and expectations for an LMS, which could help improve the system, design more relevant LMS training, and ensure greater LMS use by instructors irrespective of academic discipline. 


\section{Acknowledgements}

We thank all the instructors who volunteered their time to participate in the online survey and shared their LMS experiences with us. We also thank the reviewers for their helpful critique during the preparation of this manuscript.

\section{References}

Allen, I. E., \& Seaman, J. (2010). Class differences: Online education in the United States. Needham, MA: Babson Survey Research Group.

Arbaugh, J. B. (2005). How much does "subject matter" matter? A study of disciplinary effects in on-line MBA courses. Academy of Management Learning \& Education, 4(1), 57-73. https://doi.org/10.5465/amle.2005.16132549

Biglan, A. (1973a). The characteristics of subject matter in different academic areas. Journal of Applied Psychology, 57(3), 195-203. https://doi.org/10.1037/h0034701

Biglan, A. (1973b). Relationships between subject matter characteristics and the structure and output of university departments, Journal of Applied Psychology, 57(3), 204-213. https://doi.org/10.1037/h0034699

Buzzard, C., Crittenden, V. C., Crittenden, W. F., \& McCarty, P. (2011). The use of digital technologies in the classroom: A teaching and learning perspective. Journal of Marketing Education, 33(2), 131139. https://doi.org/10.1177/0273475311410845

Dahlstrom, E., Brooks, D. C., \& Bichsel, J. (2014). The current ecosystem of learning management systems in education: Student, faculty, and IT perspectives. Louisville, CO: EDUCAUSE Center for Analysis and Research. Retrieved from https://library.educause.edu//media/files/library/2014/9/ers1414-pdf.pdf

Ertmer, P. A., Ottenbreit-Leftwich, A. T., Sadik, O., Sendurur, E., \& Sendurur, P. (2012). Teacher beliefs and technology integration practices: A critical relationship. Computers \& Education, 59, 423-435. https://doi.org/10.1016/j.compedu.2012.02.001

Fathema, N., Shannon, D., \& Ross, M. (2015). Expanding the technology acceptance model (TAM) to examine faculty use of learning management systems (LMS). Journal of Online Learning and Teaching, 11(2), 210-233. Retrieved from http://jolt.merlot.org/Vol11no2/Fathema_0615.pdf

Fathema, N., \& Sutton, K. (2013). Factors influencing faculty members' learning management systems adoption behavior: An analysis using the technology acceptance model. International Journal of Trends in Economics Management \& Technology, 2(6), 20-28. Retrieved from http://ijtemt.org/vol2issue6/Factors influencing_faculty members.php

Guidry, K., \& BrckaLorenz, A. (2010). A comparison of student and faculty academic technology use across disciplines. EDUCAUSE Quarterly, 33(3), 1-12. Retrieved from https://er.educause.edu/articles/2010/9/a-comparison-of-student-and-faculty-academic-technologyuse-across-disciplines

Instructure (2019). The learning platform that helps great education happen. Retrieved from https://www.instructure.com/canvas/

Jaschik, S., \& Lederman, D. (2014). The 2014 Inside Higher Ed survey of faculty attitudes on technology: A study by Gallup and Inside Higher Ed. Retrieved from https://www.insidehighered.com/sites/default/server_files/files/IHE-FacTechSurvey2014\%20final.pdf

Kale, U., \& Goh, D. (2014). Teaching style, ICT experience and teachers' attitudes toward teaching with Web 2.0. Education and Information Technologies, 19(1), 41-60. https://doi.org/10.1007/s10639-0129210-3

Kim, S. W., \& Leet, M. G. (2008). Validation of an evaluation model for learning management systems. Journal of Computer Assisted Learning, 24(4), 284-294.https://doi.org/10.1111/j.13652729.2007.00260.x

Lam, P., McNaught, C., Lee, J., \& Chan, M. (2014). Disciplinary difference in students' use of technology: Experience in using eLearning strategies and perceptions towards eLearning. Computers and Education, 73, 111-120. https://doi.org/10.1016/j.compedu.2013.12.015

Lee, Y., Kozar, K. A., \& Larsen, K. (2003). The technology acceptance model: Past, present, and future. Communications of the Association for Information Systems, 12(50), 752-780. https://doi.org/10.17705/1 cais.01250

Lowenthal, P. R., Wilson, B., \& Parrish, P. (2009, October). Context matters: A description and typology of the online learning landscape. Paper presented at the 2009 Association for Educational 
Communications and Technology International Convention, Louisville, KY. Retrieved from https://docgo.net/view-doc.html?utm_source=context-matters-a-description-and-typology-of-theonline-learning-landscape

Malhotra, Y. \& Galletta, D. F. (1999). Extending the technology acceptance model to account for social influence: Theoretical bases and empirical validation. Proceedings of the 32nd Annual Hawaii International Conference on System Sciences, 32, 6-14. https://doi.org/10.1109/hicss.1999.772658

Meyen, E. L., Tange, P., \& Lian, C. H. T. (1999). Developing online instruction: Partnership between instructors and technical developers. Journal of Special Education Technology, 14(1), 18-31. https://doi.org/10.1177/016264349901400102

Miles, M. B., \& Huberman, A. M. (1994). Qualitative data analysis: An expanded sourcebook. Thousand Oaks, CA: Sage.

Neumann, R., Parry, S., \& Becher, T. (2002). Teaching and learning in their disciplinary contexts: A conceptual analysis. Studies in Higher Education, 27(4), 405-418. https://doi.org/10.1080/0307507022000011525

Orfanou, K., Tselios, N., \& Katsanos, C. (2015). Perceived usability evaluation of learning management systems: Empirical evaluation of the system usability scale. International Review of Research in Open and Distributed Learning, 16(2), 227-246. https://doi.org/10.19173/irrodl.v16i2.1955

Panda, S., \& Mishra, S. (2007). E-learning in a mega open university: Faculty attitude, barriers and motivators. Educational Media International, 44(4), 323338. https://doi.org/10.1080/09523980701680854

Pituch, K. A, \& Lee, Y.-K. (2006). The influence of system characteristics on e-learning use. Computers Education, 47, 222-244. https://doi.org/10.1016/j.compedu.2004.10.007

Sanga, M. W. (2016). An analysis of technological issues emanating from faculty transition to a new learning management system. Quarterly Review of Distance Education, 17(1), 11-21. Retrieved from https://eric.ed.gov/?id=EJ1142963

Sauro, J. (2011). Measuring usability with the System Usability Scale (SUS). Retrieved from https://measuringu.com/sus/

Sinclair, J., \& Aho, A.-M. (2017). Experts on super innovators: Understanding staff adoption of learning management systems. Higher Education Research \& Development, 37(1), 158-172. https://doi.org/10.1080/07294360.2017.1342609

Smith, G. G., Torres-Ayala, A. T., \& Heindel, A. J. (2008). Disciplinary differences in e-learning instructional design. Journal of Distance Education, 22(3), 63-88. Retrieved from https://files.eric.ed.gov/fulltext/EJ812564.pdf

Soomro, K. A., Zai, S. Y., \& Jafri, I. H. (2015). Competence and usage of Web 2.0 technologies by higher education faculty. Educational Media International, 52(4), 284-295. https://doi.org/10.1080/09523987.2015.1095522

Spotts, T. H. (1999). Discriminating factors in faculty use of instructional technology in higher education. Educational Technology and Society, 2(4), 92-99. Retrieved from https://citeseerx.ist.psu.edu/viewdoc/download?doi=10.1.1.39.8480\&rep=rep1\&type=pdf

Steel, C. (2009). Reconciling university teacher beliefs to create learning designs for LMS environments. Australasian Journal of Educational Technology, 25(3), 399-420. https://doi.org/10.14742/ajet.1142

Weaver, D., Spratt, C., \& Nair, C. (2008). Academic and student use of a LMS: Implications for quality. Australasian Journal of Educational Technology, 24(1), 30-41. https://doi.org/10.14742/ajet.1228

Wentworth, N., Graham, C. R., \& Tripp, T. (2008). Development of teaching and technology integration: Focus on pedagogy. Computers in the Schools, 25(1/2), 64-80. https://doi.org/10.1080/07380560802157782

West, R., Waddoups, G., \& Graham, C. (2007). Understanding the experiences of instructors as they adopt a course management system. Educational Technology Research \& Development, 55(1), 1-26. https://doi.org/10.1007/s11423-006-9018-1

Woodell, J. \& Garofoli, E. (2003). Faculty development and the diffusion of innovations. Syllabus, 16(6), 15-17. Retrieved from https://eric.ed.gov/?id=EJ668280

Zayim, N., Yildirim, S., \& Saka, O. (2006). Technology adoption of medical faculty in teaching: Differentiating factors in adopter categories. Educational Technology \& Society, 9(2), 213-222. Retrieved from https://eric.ed.gov/?id=EJ836835

Zheng, Y., Wang, J., Doll, W., Deng, X., \& Williams, M. (2018). The impact of organizational support, technical support, and self-efficacy on faculty perceived benefits of using learning management system. Behavior \& Information Technology, 37(4), 311-319.

https://doi.org/10.1080/0144929x.2018.1436590 
Corresponding author: Nafsaniath Fathema, fathema@wisc.edu

Copyright: Articles published in the Australasian Journal of Educational Technology (AJET) are available under Creative Commons Attribution Non-Commercial No Derivatives Licence (CC BY-NCND 4.0). Authors retain copyright in their work and grant AJET right of first publication under CC BYNC-ND 4.0.

Please cite as: Fathema, N., \& Akanda, M. H. (2020). Effects of instructors' academic disciplines and prior experience with learning management systems: A study about the use of Canvas. Australasian Journal of Educational Technology, 36(4), 113-125. https://doi.org/10.14742/ajet.5660 